\title{
Recruitment Characteristics of Nerve Fascicles Stimulated by a Multigroove Electrode
}

\author{
Paul Koole, Jan Holsheimer, Johannes J. Struijk, and Anton J. Verloop
}

\begin{abstract}
The recruitment characteristics of fascicle-selective nerve stimulation by a multigroove electrode have been investigated both theoretically and in acute experiments. A threedimensional (3-D) volume conductor model of fascicles in a multigroove device and a model of myelinated nerve fiber stimulation were used to calculate threshold stimuli of nerve fibers in these fascicles. After their exposition, fascicles from rat sciatic nerve were positioned in different grooves of appropriate sizes and stimulated separately. The device appeared to be suitable for fascicle-selective stimulation, because both computer simulations and acute animal experiments showed that crosstalk between neighboring fascicles is not a problem, even when monopolar stimulation was used. The threshold stimulus was lower for a small fascicle than for a large one. When the amount of (conducting) medium between contact and perineurium or its conductivity was reduced, threshold stimuli were lower. Moreover, simulations predict that the slopes of recruitment curves are smaller and inverse recruitment order is less pronounced. Simulations also showed that a small contact is preferable to a large one, because a small contact gives a slightly smaller slope of the recruitment curve. Both experimentally and theoretically a significantly smaller slope of recruitment curves was obtained by stimulation with a cathode and an anode at opposite sides of the fascicle, driven by two current sources giving simultaneous pulses with different, but linearly dependent amplitudes.
\end{abstract}

Index Terms-Electrical stimulation, fascicle stimulation, neural prostheses, nerve stimulation, recruitment.

\section{INTRODUCTION}

$\mathbf{T}$ HE design of appropriate stimulating electrodes is an important aspect in the development of systems for functional electrical stimulation (FES). The goal of FES research is the development of aids for brain or spinal cord injured patients to regain functional use of paralyzed muscles. Problems encountered by actual FES-systems are, for instance, muscle fatiguability and lack of muscle selectivity [1]. These problems cannot be solved when using surface electrodes, because muscle selectivity of these electrodes is limited. Therefore, several types of implantable electrodes have been developed, e.g., intramuscular [2]-[4], epimysial [5], nerve cuff [6], [7], epineural [8] and intraneural [9]-[12] electrodes. Each type has its advantages and disadvantages depending on the specific application. Much effort is still needed to improve electrode-types or to develop new ones [13], [14].

In direct nerve stimulation one may take advantage of the natural specificity of fascicles in peripheral nerves. Close to

Manuscript received December 11, 1995; revised December 4, 1996.

The authors are with the Department of Electrical Engineering, Institute for Biomedical Technology, University of Twente, P.O. Box 217, 7500 AE Enschede, The Netherlands.

Publisher Item Identifier S 1063-6528(97)02384-7. the spinal cord fascicles have a mixed composition with regard to the muscles they innervate. However, toward the periphery they fuse and divide repeatedly, resulting in a redistribution of nerve fibers. Approaching nerve branching points, fascicles become more specific for a group of muscles, a single muscle or even part of a muscle [15]. It can be attractive to take advantage of this anatomical subdivision of peripheral nerves for selective stimulation of muscles [13], [16]. Surgically, it will have some advantage to be able to position a number of electrodes with different targets close together.

Extraneural electrodes can be used for fascicle-selective stimulation to activate muscles or parts of muscles selectively [6], [17]-[20]. It has been investigated how the degree of selectivity depends on the geometries of the electrode contacts of a multipolar cuff electrode [19]. Modeling studies of extraneural stimulation [16], [17], [21] predicted that selective stimulation is limited to fascicles lying superficially in the nerve. A recent modeling study, however, indicated that fibers far from the electrode can be activated selectively when fibers close to the electrode are inactivated first by subthreshold prepolarizing pulses [22].

An alternative is the development of electrodes closer to the fascicles. In a multigroove electrode, as presented in this paper, the various fascicles are placed in different grooves. Selective stimulation of a fascicle using such a device is not a problem, as will be shown in this paper. Similar to selective stimulation in a nerve trunk by a multipolar cuff electrode [19], the multigroove electrode offers opportunities to influence the fascicle recruitment characteristics by the selection of electrode contacts, contact dimensions and stimulus parameters. The multigroove electrode resembles the bookelectrode developed by Brindley et al. for sacral anterior root stimulation [23], [24], which, however, is much larger. The groove diameters of the multigroove electrode approximately fit the corresponding fascicles. The grooves can be considered as flexible, open cuffs.

In this paper model calculations are presented which were helpful in designing a prototype of a multigroove electrode and in understanding its properties. Some preliminary results have been published earlier [25]. Acute animal experiments were done as a first step in evaluating the stimulation characteristics of this electrode. Branches of the rat sciatic nerve (the common peroneal nerve and tibial nerve) were stimulated, whereas twitch forces of the extensor digitorum longus (EDL) and triceps surae muscles were measured. No conclusions about possible nerve damage can be drawn from the reported experiments, because chronic experiments were not executed. 


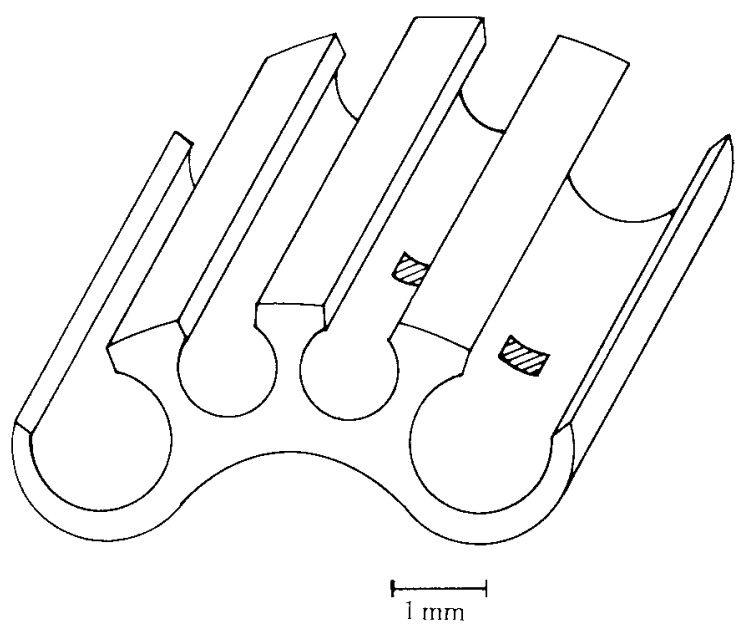

(a)

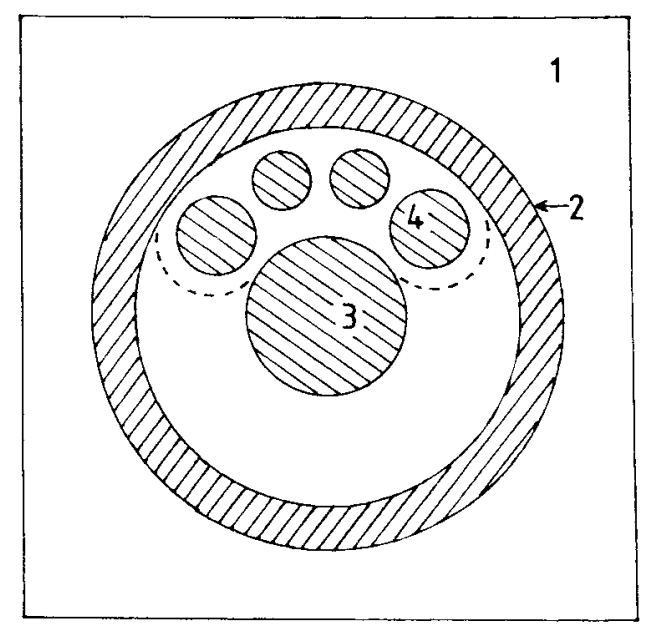

(b)

Fig. 1. (a) Multigroove electrode with electrical contacts (shaded) visible in two grooves; connecting wires at back side. (b) Transverse view of the teflon mold; plate (1), tube (2), cylinder (3), and small cylinders (4).

The effects of fascicle diameter, electrode contact size and conductivity of the intermediate layer between contact and fascicle on crosstalk between neighboring fascicles and their recruitment characteristics were evaluated, using monopolar cathodal stimulation. Furthermore, it was examined how recruitment characteristics changed by the use of an extra, independently controlled anode transversely opposite to the stimulating cathode.

\section{MATERIALS AND METHODS}

\section{A. Multigroove Electrode}

A multigroove electrode consisting of four grooves, each containing a single contact for monopolar stimulation, is shown in Fig. 1(a). A nerve length of $10-15 \mathrm{~mm}$ has to be dissected into its fascicles and each fascicle has to be placed in a groove. The grooves have approximately the same diameters as the fascicles, which is allowed when the device is made of a flexible material.
In this study electrodes with only two grooves, being sufficient to investigate the basic properties of the multigroove electrode, were used.

Multigroove electrodes for the acute experiments of this study were fabricated as follows. Flat contacts $(90 \% \mathrm{Pt}-10 \%$ Ir, $0.1 \mathrm{~mm}$ thickness) were soldered with gold to $0.05 \mathrm{~mm}$ Isonel insulated wires $(90 \% \mathrm{Pt}-10 \%$ Ir). The devices were made in the following way, using a teflon mold. A teflon cylinder ( $3 \mathrm{~mm}$ diameter), a teflon tube ( $7 \mathrm{~mm}$ inner diameter) around it and small teflon cylinders $(2 \mathrm{~mm}$ apart, fitting the groove diameters) in between were fixed perpendicular to a $5 \mathrm{~mm}$ teflon plate [see transverse section in Fig. 1(b)]. The space between the outer tube (2) and the inner cylinder (3) of the mold was filled with silicone rubber (Dow Corning, Silastic 734 RTV). After removing the teflon mold, most of the silicone rubber aside the outer grooves was cut as indicated by the dotted line in Fig. 1(b), whereas the length of the device was made 5-8 mm and a cleft was cut on top of each groove. Next, an insulated wire was pulled through a small hole, drilled in the bottom of the groove, until the connected Pt-Ir contact was at the bottom. Both contacts and connecting wires were secured with silicone rubber, and the wires left the device as a helical bundle. The dimensions of grooves and contacts used in the experiments of this study are given below.

\section{B. Nerve Stimulation Model}

1) Volume-Conductor Model: A three-dimensional model of the electrical tissue properties was used. It was composed of $56 \times 56 \times 56$ rectangular volume elements. A multigroove electrode consisting of two grooves was modeled. Each groove contained a fascicle $(f)$ surrounded by perineurial tissue $(p)$. Cross sections of some versions of the model, used for different simulations, are shown in Fig. 2. The length $(z-$ direction) of the multigroove device $(d)$ was $8 \mathrm{~mm}$. Next to the ends of the grooves the device was replaced by surrounding tissue $(s)$. An intermediate layer $(i)$ was modeled between the perineurium and the device. Two different conductivities of the intermediate layer have been used, because in acute experiments a well-conducting saline layer (Ringer solution) will be present, whereas in chronic experiments a lowconductivity layer of fibrous tissue will encapsulate the device [26].

The potential distribution within the volume-conductor model was calculated by solving the Laplace equation numerically using red-black Gauss-Seidel iteration [27]. After each half iteration step an overrelaxation factor of about 1.99 was used.

In most simulations, when small contacts of only a few grid points were modeled, the contacts were defined as current sources. Large contacts, however, would cause unequal potential values at the grid points of the contact. Therefore, large contacts were defined by imposing a fixed potential at their grid points (Dirichlet condition). Zero potential was imposed at the surface of the model to represent the reference electrode. To reduce the effect of the finite dimensions of the model, a boundary layer (b) with a low conductivity was added, thus imitating an increased distance to the reference electrode. 


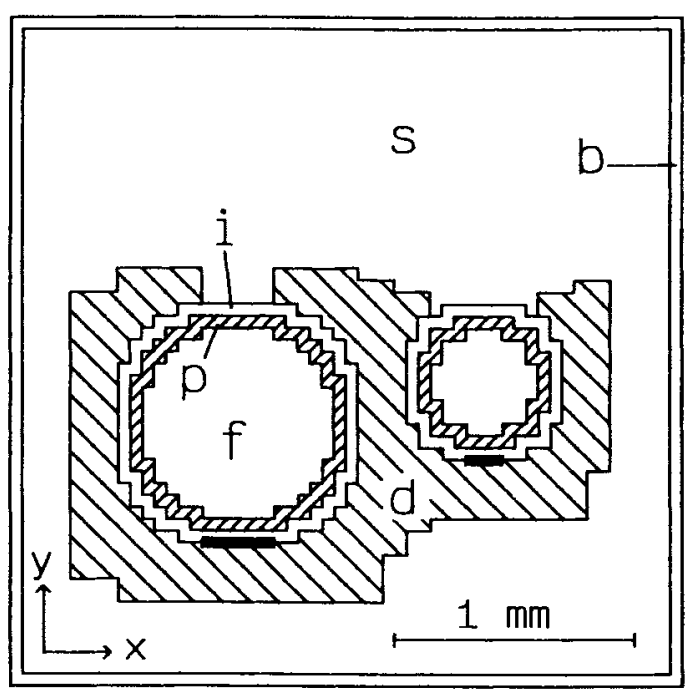

(a)

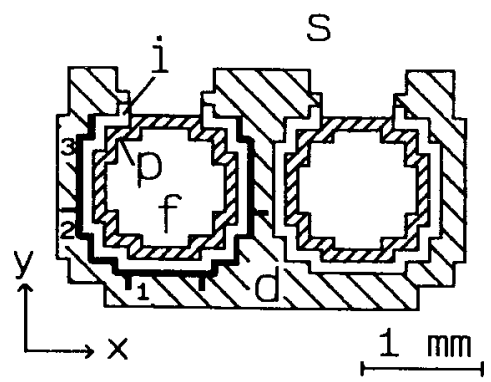

(b)
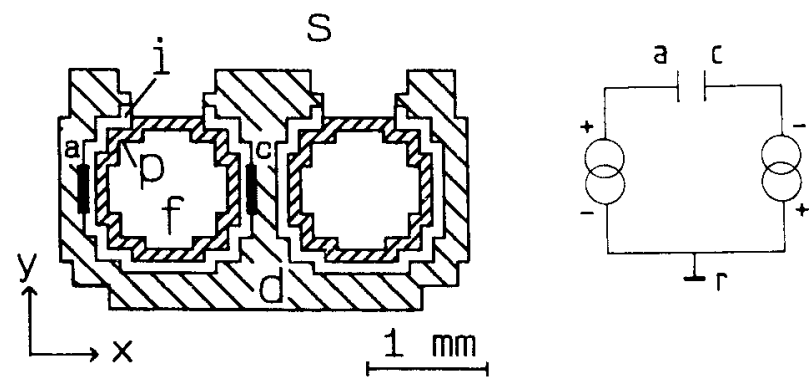

(c)

Fig. 2. Cross sections of different volume conductor models (normal to groove axes); electrode contacts represented by thick lines; for compartmen codes $(b, d, f, i, p, s)$ see Table I and text: (a) Two fascicles with different diameters; thickness of layer $i$ : $50 \mu \mathrm{m}$; contacts for the large and small fascicle are 0.35 and $0.2 \mathrm{~mm}$ ( $x$-direction) and $0.8 \mathrm{~mm}$ ( $z$-direction). (b) Two identical grooves and fascicles; thickness of layer $i$ : $100 \mu \mathrm{m}$; symmetrical contacts (shown in left groove) are 0.7 (1), 2.1 (2), and $3.9 \mathrm{~mm}$ (3) wide and $0.8 \mathrm{~mm}$ long ( $z$-direction); for shape of contacts see also Fig. 5(a); boundary of the model not shown. (c) Model for stimulation with two current sources; same geometry as in $b$; cathode $(c)$ and anode $(a)$ are $0.5 \mathrm{~mm}$ ( $y$-direction) and $0.8 \mathrm{~mm}$ ( $z$-direction); wiring diagram shows two current sources connected to anode, cathode and common reference $(r)$ at model boundary.

The conductivities of the compartments of the model are presented in Table I. The conductivity of the perineurium was derived from Weerasuriya et al. [28], assuming a $40 \mu \mathrm{m}$ thickness of the perineurium in their experiments. It has been suggested that the thickness of the perineurium roughly equals $5 \%$ of the diameter of a fascicle $[15, \mathrm{p} .41]$. The thickness of the modeled perineurium was too large in comparison with
TABLE I

Conductivities of the Volume Conductor Model Compartments

\begin{tabular}{clll}
\hline code & compartment & $\sigma(\mathbf{\Omega m})^{-1}$ & ref. \\
\hline f & fascicle (x,y-plane) & 0.08 & 29 \\
f & fascicle (z-direction) & 0.5 & 29 \\
p & perineurium & $8.4 \cdot 10^{-4}$ & 28 \\
S & surrounding tissue & 0.1 & \\
i & fibrous tissue & 0.1 & \\
i & saline (.9 M NaCl) & 2.0 & 29 \\
d & insulating device & $10^{-6}$ & \\
b & boundary layer & $10^{-4}$ & \\
\hline
\end{tabular}

the diameters of the fascicles. Therefore, the conductivity of the perineurium, perpendicular to its surface, was increased by a correction factor. The conductivity of the perineurium, parallel to its surface, was reduced by the same factor. The conductivities of the surrounding tissue and fibrous tissue were given a value in the range of conductivities of muscle tissue and epineurium [16], [29]. The insulating material of the multigroove device was given a very low conductivity. A further reduction of this conductivity by a factor of ten did not affect the calculated potential distribution, indicating that the chosen value was low enough for numerical representation of an insulator.

2) Nerve Fiber Model: Nerve fiber excitation was modeled using the network description of a myelinated nerve fiber in an external electrical field as introduced by McNeal [30]. Monophasic, $60 \mu \mathrm{s}$ rectangular pulses were used and the extracellular potentials at the nodes of Ranvier were derived from the calculated potential distribution. The dynamic electrical properties of the nodes of Ranvier were modeled [31] according to the data from voltage-clamp experiments on rabbit myelinated nerve fibers [32] and adapted to a temperature of $37^{\circ} \mathrm{C}$. All nodes of the fiber model were made excitable.

Nerve fiber excitation depends on the distance between the cathode and the nearest node of Ranvier. This distance consists of two components: the distance between cathode and nerve fiber in the $x, y$-plane, and a component in the $z$-direction $\left(L_{0}\right)$ between the midplane of the cathode and the nearest node of Ranvier. $L_{0}$ has a value between 0 and $0.5 L$ ( $L$ is the internodal distance). Threshold stimuli were defined as the minimum current (or voltage) of a $60 \mu$ s pulse to excite a nerve fiber of given diameter and position.

3) Calculation of Recruitment Curves: Modeling results are presented by two types of recruitment curves. Nerve recruitment curves show the fraction of recruited nerve fibers of a single diameter in a fascicle as a function of stimulus amplitude. It was assumed that the distribution of nerve fibers of the same diameter over the cross section of a fascicle is uniform, since experimental data on this distribution were not available. The distribution of $L_{0}$-values 
TABLE II

Number of $\alpha$ Motor Fibers InNervating the EDL of the Cat [33]; Weight Factors Calculated by (1) and Normalized to the MaXimum Value; for D the Central Value of Each Interval Was Used; $v=6 \bullet D$

\begin{tabular}{ccc}
\hline $\mathbf{D}(\boldsymbol{\mu} \mathbf{m})$ & $\begin{array}{c}\text { number of } \\
\boldsymbol{\alpha} \text {-fibers }\end{array}$ & $\begin{array}{c}\text { weight } \\
\text { factor }\end{array}$ \\
\hline $9-10$ & 5 & 0.01 \\
$10-11$ & 8 & 0.03 \\
$11-12$ & 17 & 0.12 \\
$12-13$ & 41 & 0.51 \\
$13-14$ & 46 & 1.00 \\
$14-15$ & 10 & 0.38 \\
$15-16$ & 1 & 0.07 \\
\hline
\end{tabular}

was assumed to be uniform between 0 and $0.5 L$. Threshold stimuli were calculated for nerve fibers positioned centrally in each square element (in the $x, y$-plane) inside the fascicle. For $L_{0}$ ten equidistant values were chosen from $0.025 \mathrm{~L}$ to $0.475 \mathrm{~L}$. Recruitment at a certain stimulus amplitude was defined as the fraction (between 0 and 1 ) of calculated thresholds being lower than this stimulus amplitude. The stimulus amplitudes ( $x$-axis of recruitment curves) were plotted on a logarithmic scale. The slope of such a recruitment curve is dimensionless, as is shown below. The slopes of two recruitment curves will be identical when an increase of the stimulus amplitude by some factor results in the same increase of recruitment for both curves.

Force recruitment curves represent the weighted sum of a number of nerve recruitment curves from several fiber diameters (similar to experimental recruitment curves), normalized to maximum force. The weight factors depended on the diameter distribution of the motor nerve fibers and on the relation between nerve fiber diameter and twitch force (or tetanic force) of the corresponding motor unit. Boyd and Davey [33] presented the diameter distribution of $\alpha$ motor-fibers in several muscles of the cat. The maximum tetanic force $(F)$ of a motor unit was shown to be related to the conduction velocity $(v)$ of the motor nerve fibers in several fast twitch muscles [34]. These experimental data can be approximated by the following equation

$$
F=\text { constant } \cdot e^{0.09 \cdot v} \text {. }
$$

The ratio of conduction velocity $v(\mathrm{~m} / \mathrm{s})$ and nerve fiber diameter $D(\mu \mathrm{m})$ is approximately 6 [33]. Weight factors for the EDL of the cat, based on these data, are shown in Table II. Diameter distributions of motor nerve fibers of common peroneal nerve and tibial nerve of the rat were not available. Because simulations showed that the resulting force recruitment curves are only slightly affected by small changes of the diameter distribution, the weight factors of Table II were used for all simulations presented.
4) Data Analysis: Several parameters were derived from the recruitment curves. The amplitude $A_{10}$ is the stimulus amplitude at which $10 \%$ recruitment was attained. The parameter $A_{10}$ was used because it is better defined than the threshold stimulus. For the same reason the stimulus amplitude $A_{90}$ was used instead of the amplitude where maximum recruitment was attained. Assuming that fascicle 1 lies in the groove with the active cathode and fascicle 2 is a fascicle in a neighboring groove, crosstalk from the active cathode to fascicle 2 is quantified by the parameter $R$

$$
R=A_{2,10} / A_{1,90}
$$

where $A_{1,90}$ is the stimulus amplitude at which $90 \%$ recruitment was attained in fascicle 1 and $A_{2,10}$ is the stimulus amplitude related to $10 \%$ recruitment in fascicle 2 . If $R<1$ the recruitment curves will overlap.

The slope $S_{50}$ at $50 \%$ recruitment was calculated by using the least-squares method to fit the interval of the recruitment curve between 40 and $60 \%$ recruitment $(0.4$ and 0.6 for a normalized curve) to a linear approximation. So $S_{50}$ was calculated by

$$
S_{50}=\frac{0.6-0.4}{\log A_{60}-\log A_{40}} .
$$

This slope is dimensionless because normalized recruitment in the numerator is dimensionless and $\log A_{60}-\log A_{40}=$ $\log A_{60} / A_{40}$ in the denominator is dimensionless.

The (inverse) recruitment order was quantified by the parameter Ir

$$
\mathrm{Ir}_{p}=\frac{A_{p, l}-A_{p, h}}{A_{p, h}}
$$

where $A_{p, l}$ and $A_{p, h}$ are stimulus amplitudes at $p$ percent recruitment for $D=9.5$ and $15.5 \mu \mathrm{m}$, respectively. Physiological recruitment order would result in a negative value of Ir. Positive values, generally obtained in artificial stimulation, indicate an inverse recruitment order. Although the parameter Ir cannot be considered as an "absolute" measure of (inverse) recruitment order, a lower positive value represents a less pronounced inverse recruitment order than a higher value. In artificial stimulation (inverse) recruitment order not only depends on the diameters of the nerve fibers, but on the positions of the nerve fibers and their nodes relative to the cathode as well. Therefore, both $\operatorname{Ir}_{10}$ and $\operatorname{Ir}_{50}$ will be calculated.

\section{Animal Experiments}

Multigroove devices with two grooves were used in acute experiments on eight rats (Wistar, male, 3 months or older, $0.3-0.6 \mathrm{~kg})$ under sodium pentobarbital anaesthesia $(70 \mathrm{mg} / \mathrm{kg}$ i.p., additional doses as required). The EDL and triceps surae of the right hind limb were exposed and gently freed from surrounding tissue. The regions of nerve and blood supply were not encroached on. The distal tendons were cut and connected to a multiforce transducer. The position of the femur was fixed.

The sciatic nerve was gently exposed and split in a proximal direction, starting at its bifurcation. The two branches or 


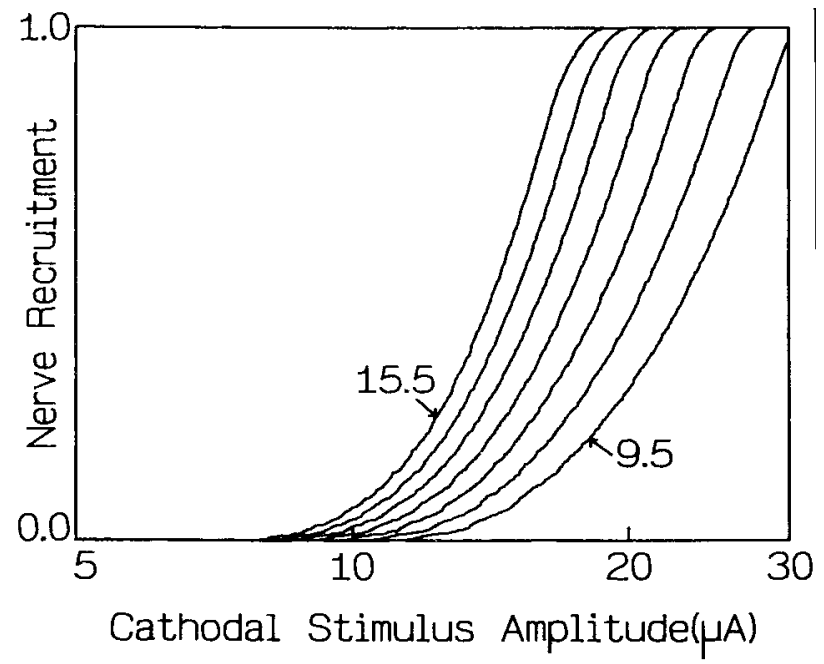

Fig. 3. Nerve recruitment curves, calculated for the large fascicle in the model of Fig. 2(a), the nerve fiber diameter $(D)$ increasing in steps of 1.0 from 9.5 to $15.5 \mu \mathrm{m}$.

fascicles (further called tibial nerve and common peroneal nerve) and their environment were moistened with Ringer solution. Each branch was placed in a groove. Depending on the caliber of the peroneal and tibial nerves, groove diameters were $1.0 \mathrm{~mm}$ for the tibial nerve and $0.5 \mathrm{~mm}$ for the peroneal nerve, or 1.2 and $0.8 \mathrm{~mm}$, respectively. Groove length was 5 $\mathrm{mm}$ or $8 \mathrm{~mm}$. The contact length ( $z$-direction) was $500 \mu \mathrm{m}$. The contact width (in the $x, y$-plane) was $300 \mu \mathrm{m}$ for the larger groove and $150 \mu \mathrm{m}$ for the smaller one, unless mentioned otherwise. A reference electrode was placed in the biceps femoris muscle of the right hind limb, at a distance of about $2 \mathrm{~cm}$ from the multigroove electrode.

During the experiment the rat was lying on a heating table. The exposed tissues were prevented sufficiently from cooling down and from dessication by a warm water-saturated airflow. Generally, the common peroneal nerve or the tibial nerve was stimulated monopolarly, using cathodic monophasic rectangular current pulses, having a pulsewidth of $60 \mu \mathrm{s}$. The time interval between stimulating pulses was at least $2 \mathrm{~s}$. In some stimulation series a groove with two contacts opposite to one another was used. Each contact was fed by its own current source, as shown in Fig. 2(c). The two sources had the distant reference electrode in common. Monophasic, $60 \mu \mathrm{s}$ rectangular current pulses were given simultaneously at both contacts, cathodic for one contact and anodic for the other one.

The twitch forces produced by the EDL (innervated by the common peroneal nerve), and the triceps surae (composed of gastrocnemius and soleus, and innervated by the tibial nerve) were measured. Both twitch forces were recorded when either the common peroneal nerve or the tibial nerve was stimulated. Stimulus amplitude was varied and force recruitment curves of EDL and triceps surae were composed.

In each experiment one or more stimulation series were given and one or more sets of recruitment curves were measured. In some experiments the sciatic nerve branches were taken out of the grooves and most of the Ringer so- lution was removed from their surface. Subsequently, they were embedded in liquid paraffin and replaced in the (dried) grooves. In this way two different conductivies could be chosen for the layer between groove and fascicle, as in the simulations. In some experiments multigroove electrodes with different contact geometries were used. In this way a number of stimulation series under different experimental conditions could be executed on the same animal.

To be able to compare the slopes of experimental and calculated recruitment curves, twitch forces were normalized to the maximum twitch force and current scales were plotted logarithmically. The parameters $S_{50}, A_{10}, A_{90}$, and $R$, defined in Section II-B4 for calculated recruitment curves, were derived from the experimentally obtained curves as well.

\section{RESULTS}

\section{A. Monopolar Stimulation}

Fig. 3 shows calculated nerve recruitment curves for fibers of various diameters lying within the large fascicle in Fig. 2(a). A layer of fibrous tissue was around the perineurium of the fascicles (layer $i$ ). Monopolar stimulation (current source) was provided by the contact at the bottom of the larger groove. A high degree of overlap exists between the ranges of stimulus amplitudes necessary to activate fibers of different sizes. The slope $S_{50}$ varies from 3.5 (for $D=9.5 \mu \mathrm{m}$ ) to 4.7 (for $D=15.5 \mu \mathrm{m})$. The force recruitment curve calculated from these data and shown in Fig. 4(a), very much resembles the calculated nerve recruitment curve for $D=13.5 \mu \mathrm{m}$. The force recruitment curve calculated for the small fascicle, when stimulation is provided by the contact at the bottom of the smaller groove, is also shown in Fig. 4(a). Both curves in Fig. 4(a) have a very small slope at low recruitment levels. The calculated force recruitment curves shown in Fig. 4(b) were obtained when the fibrous tissue layer was replaced by a saline layer between contact and perineurium.

Parameters $A_{10}, S_{50}$ and $R$, derived from the simulated curves in Fig. 4(a)-(b), have been summarized in the upper half of Table III. Stimulus amplitude $A_{10}$ has a lower value for the small fascicle than for the large fascicle. Furthermore, $A_{10}$ is smaller when the intermediate layer $(i)$ has a low conductivity $\left(\sigma=0.1(\Omega \mathrm{m})^{-1}\right)$ than when this layer has a high conductivity $\left(\sigma=2.0(\Omega \mathrm{m})^{-1}\right)$. The crosstalk parameter $R$ exceeds one in all cases, which means that one fascicle is stimulated selectively.

Two experimental force recruitment curves of one experiment are shown in Fig. 4(c). The nerve and multigroove electrode were surrounded by muscle tissue and Ringer solution. The mean values and standard deviations of $A_{10}, S_{50}$, and $R$ are given in the lower part of Table III. They were obtained from 12 recruitment curves (five animals) of the EDL, when the peroneal nerve (smaller diameter) was stimulated, and from 11 recruitment curves (five animals) of the triceps surae when the tibial nerve (larger diameter) was stimulated. The EDL (common peroneal nerve) had a smaller $A_{10}$ than the triceps surae (tibial nerve). 


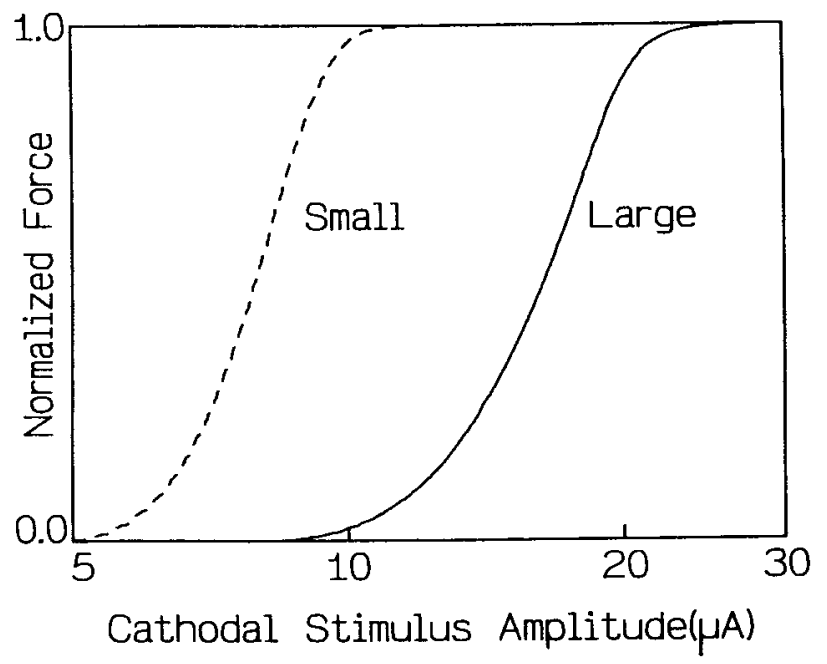

(a)

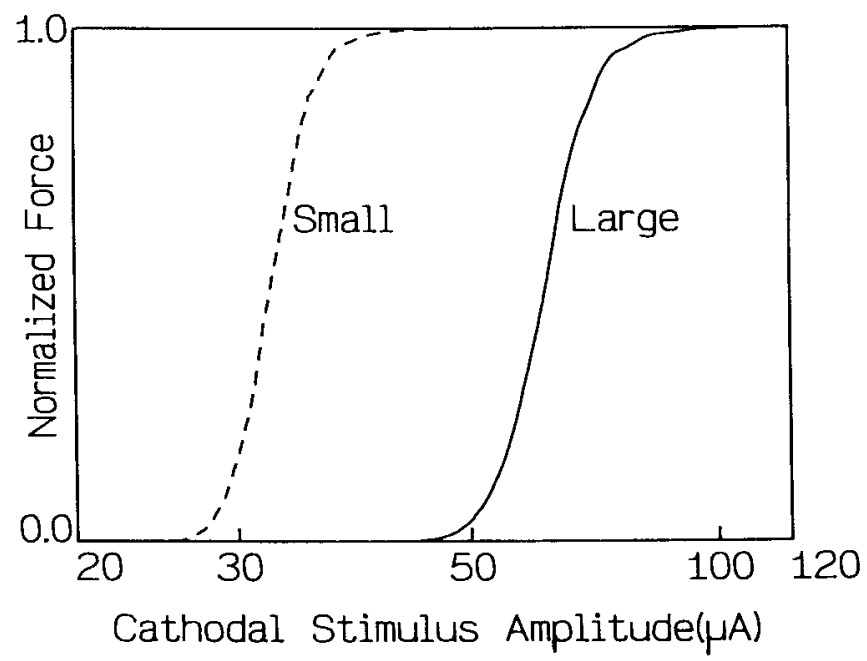

(b)

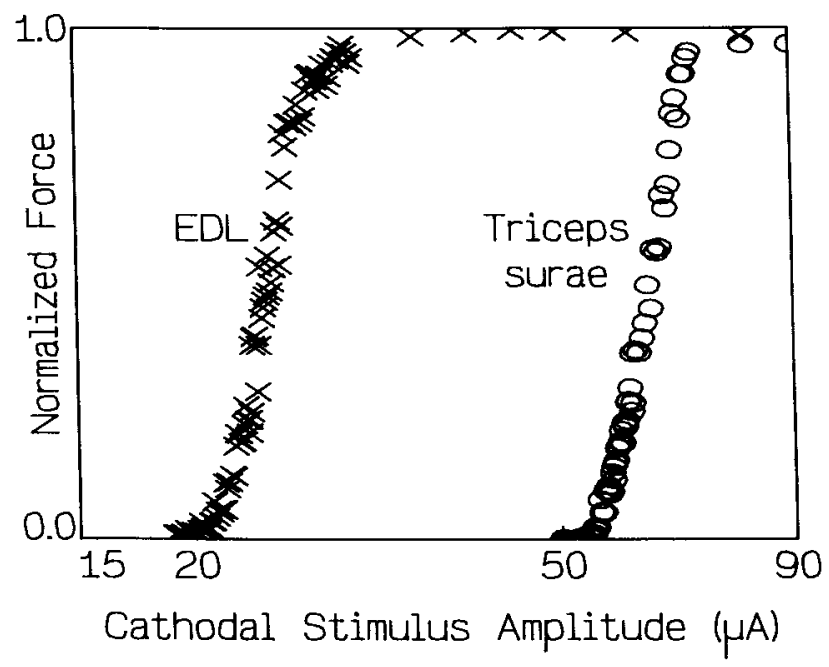

(c)

Fig. 4. (a), (b) Force recruitment curves calculated for the large and small fascicles in the model of Fig. 2(a), each stimulated by the contact in its own groove; conductivity of the intermediate layer in $a: 0.1(\Omega \mathrm{m})^{-1}$, in $b$ : $2.0(\Omega \mathrm{m})^{-1}$. (c) Experimental (force) recruitment curves for EDL (common peroneal nerve stimulation) and triceps surae (tibial nerve stimulation); maximum force of each muscle normalized to one.
TABLE III

Parameters Derived From Calculated and Experimental Force Recruitment CuRves (monopolar Stimulation)

\begin{tabular}{llccc}
\hline intermed. medium & fascicle & $\mathbf{A}_{10}(\mu \mathbf{A})$ & $\mathbf{S}_{50}$ & $\mathbf{R}$ \\
\hline $\begin{array}{llc}\text { I. simulations } \\
\sigma=2.0(\Omega \mathrm{m})^{-1}\end{array}$ & small & 29 & 9 & 7 \\
& large & 57 & 9 & 3.2 \\
$\sigma=0.1(\Omega \mathrm{m})^{-1}$ & small & 6 & 6 & 16 \\
& large & 12 & 4 & 8 \\
\hline 2. experiments & & & & \\
saline & peroneal & $27 \pm 8$ & $11 \pm 3$ & $9 \pm 5$ \\
& tibial & $89 \pm 47$ & $9 \pm 4$ & $2.1 \pm 1$ \\
liquid paraffine & peroneal & $12 \pm 4$ & $13 \pm 6$ & $8 \pm 5$ \\
& tibial & $26 \pm 9$ & $6.5 \pm 1$ & $1.7 \pm 0.4$ \\
\hline
\end{tabular}

TABLE IV

Slope $S_{50}$ of CAlculated Force Recruitment CuRves for Various Cathode Dimensions (MONOPOlar Stimulation)

\begin{tabular}{llcc}
\hline $\begin{array}{l}\text { cathode } \\
\text { length } \\
(\mathbf{z}, \mathbf{m m})\end{array}$ & $\begin{array}{c}\text { dimensions } \\
\text { width } \\
(\mathbf{x}, \mathbf{y})\end{array}$ & $\begin{array}{c}\mathbf{S}_{\mathbf{5 0}} \\
\text { with fibrous } \\
\text { tissue }\end{array}$ & $\begin{array}{c}\mathbf{S}_{50} \\
\text { no fibrous } \\
\text { tissue }\end{array}$ \\
\hline 0.8 & small & 4.1 & 2.8 \\
0.8 & intermediate & 4.7 & 2.7 \\
0.8 & large & 7.0 & 4.6 \\
\hline 0.4 & small & 4.3 & 2.8 \\
0.8 & small & 4.1 & 2.8 \\
1.2 & small & 4.5 & 2.9 \\
1.6 & small & 4.5 & 3.1 \\
\hline
\end{tabular}

In the experiments crosstalk to the neighboring fascicle usually arose only at high stimulus amplitudes. Crosstalk from the peroneal nerve to the (larger) tibial nerve arose at $A_{2,10}=320 \pm 190 \mu \mathrm{A}(n=5)$. In other experiments crosstalk did not occur in the stimulus range used. In all these cases $R$ exceeded one. When the tibial nerve was stimulated, however, threshold for the peroneal nerve was $A_{2,10}=180 \pm 140 \mu \mathrm{A}$ $(n=5)$ and $R$ had lower values, as in the simulation results.

To investigate experimentally the effect of reduced conductivities of the surrounding medium and the intermediate medium between fascicle and groove, the Ringer solution was replaced by liquid paraffin around nerve and electrode, except between contact and nerve (seven recruitment curves, four animals). The mean values of $A_{10}, S_{50}$, and $R$ of the measured recruitment curves are also shown in Table III. As in the simulations and in the experiments with Ringer solution, $A_{10}$ was lower for the (smaller) peroneal nerve than for the (larger) tibial nerve. Threshold for crosstalk from peroneal nerve to tibial nerve was $A_{2,10}=110 \pm 70 \mu \mathrm{A}(n=5)$, 


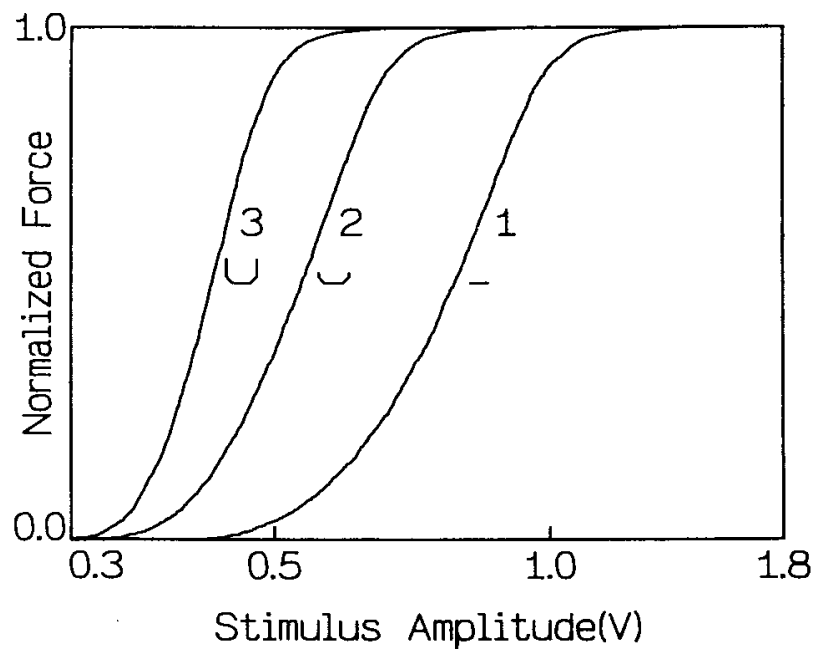

(a)

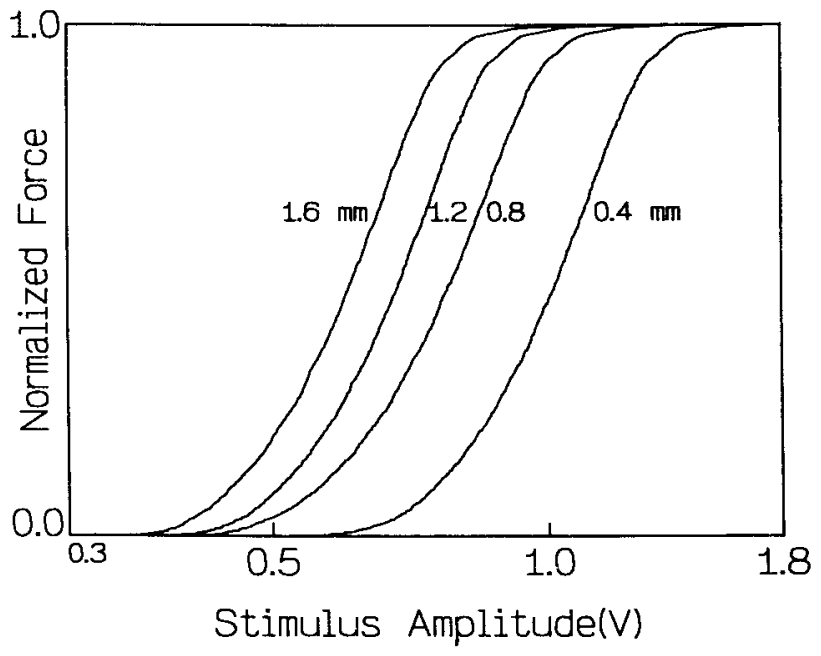

(b)

Fig. 5. (a) Force recruitment curves calculated for contacts of three differen widths, corresponding to 1, 2 and 3 in model of Fig. 2(b), and $0.8 \mathrm{~mm}$ length; monopolar stimulation. (b) Force recruitment curves calculated for contacts of different lengths ( $z$-direction) and $0.7 \mathrm{~mm}$ wide ( $x, y$-plane) in model of Fig. 2(b); monopolar stimulation.

and in the reverse direction $A_{2,10}=54 \pm 16 \mu \mathrm{A}(n=5)$. Again, $R$ was smaller when the tibial nerve was stimulated than at peroneal nerve stimulation.

\section{B. Effect of Cathode Dimensions}

The effect of cathode dimensions on the recruitment characteristics of a fascicle was studied using the model of Fig. 2(b). The intermediate layer $(i)$ was fibrous tissue and a voltage source was used instead of a current source. Fig. 5(a) shows calculated force recruitment curves for three contacts [shown in Fig. 2(b)], having different dimensions in the $x, y$-plane, but each having a length of $0.8 \mathrm{~mm}$ ( $z$-direction). The force recruitment curves of Fig. 5(b) were calculated using a contact width of $0.7 \mathrm{~mm}$ [contact 1 at the bottom of the groove in Fig. 2(b)]. The length of the contact was varied from 0.4 to $1.6 \mathrm{~mm}$. Simulations were also executed using a model without a fibrous tissue layer between device and perineurium

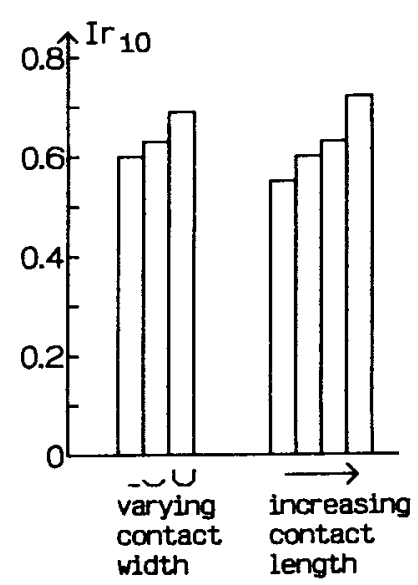

(a)

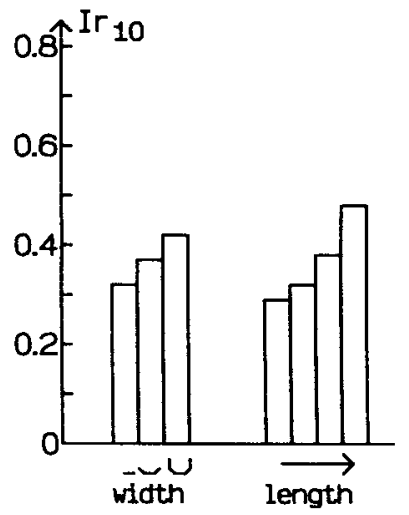

(c)

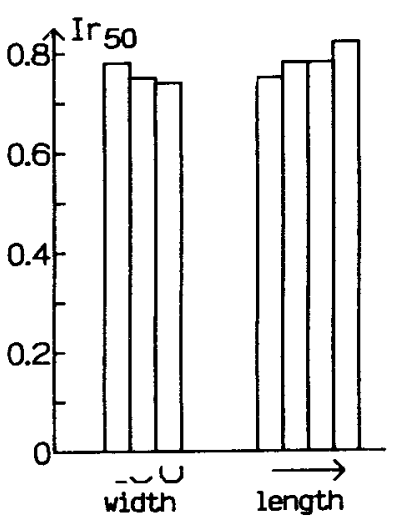

(b)

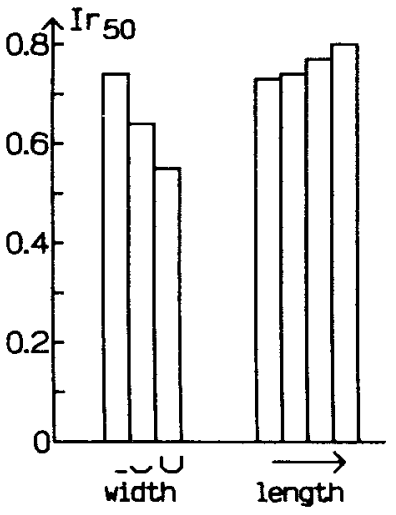

(d)
Fig. 6. Parameter Ir for (inverse) recruitment order at $10 \%\left(\operatorname{Ir}_{10}\right)$ and $50 \%$ ( Ir $\left._{50}\right)$ recruitment level; monopolar stimulation; (a) and (b) fibrous tissue layer in between contact and perineurium; (c) and (d) contact next to perineurium. Bars in each figure correspond to different contact dimensions: three contact widths and four contact lengths; bars in (a) and (b) correspond to recruitment curves of Fig. 5(a)-(b).

(recruitment curves not shown). The fascicles in this model had the same dimensions as in Fig. 2(b), but the grooves were smaller.

The slopes $S_{50}$ of the calculated force recruitment curves are given in Table IV. The slope of the recruitment curve was large for the contact with a large width in the $x, y$-plane. Note also the small slope at low recruitment levels (Fig. 5). Without a fibrous tissue layer in between the cathode and the perineurium, the slopes of the recruitment curves were smaller than with a fibrous tissue layer. When the length of the contact ( $z$-direction) was varied, the slope of the recruitment curve changed only by $10 \%$ [Fig. 5(b)].

To investigate whether (inverse) recruitment order depends on the dimensions of the contact, values of the parameter Ir at 10 and 50\% recruitment were calculated (Fig. 6). Ir had the lowest values at a low recruitment level when the cathode was in direct contact with the perineurium $\left[\operatorname{Ir}_{10}=0.3-0.5\right.$ in Fig. 6(c)], which means that inverse recruitment was not very strong. Ir was larger when fibrous tissue was present between cathode and perineurium. At low (10\%) recruitment level Ir decreased with decreasing contact area. However, Ir is almost 
independent of contact dimensions at a 50\% recruitment level, except that $\operatorname{Ir}_{50}$ decreased with increasing contact width in Fig. 6(d).

\section{Stimulation with Two Current Sources}

In the model of Fig. 2(c) a fascicle was stimulated by a cathode and an anode opposite to one another in the same groove $(0.5 \mathrm{~mm}$ contact width, $0.8 \mathrm{~mm}$ contact length). The intermediate layer $(i)$ was given the conductivity of fibrous tissue $\left(\sigma=0.1(\Omega \mathrm{m})^{-1}\right)$. The cathodal and anodal currents were varied independently, while the surface of the model represented the common, remote reference electrode. Fig. 7(a)-(b) show the calculated force recruitment curves. When the anodal current pulse had a fixed amplitude (20, 40 or $60 \mu \mathrm{A})$, the slope $\left(S_{50}=3.4,3.1,2.9\right.$, respectively) was smaller than the slope for monopolar cathodal stimulation (curve $c, S_{50}=4.3$ ), as shown in Fig. 7(a). When the anodal current $A_{a}$ was increased simultaneously with the cathodal current $A_{c}$, using the linear relation between $A_{a}$ and $A_{c}$ shown in the inset of Fig. 7(b), a force recruitment curve intersecting the curves of Fig. 7(a) was obtained. The slope of this force recruitment curve was much smaller $\left[S_{50}=1.7\right.$ in Fig. 7(b)].

This aspect was investigated experimentally as well. Fig. 7(c)-(d) show recruitment curves of the triceps surae obtained by stimulation of the tibial nerve. The nerve and multigroove electrode were surrounded by muscle tissue and liquid paraffin, giving a low conductivity of the environment as in the simulations of Fig. 7(a)-(b). For monopolar cathodal stimulation the slope $S_{50}$ of the recruitment curve was eight [Fig. 7(c)]. In the experiments the slope was larger when two current sources were used with a fixed value of the anodal current: $S_{50}=13$ and 19 for $A_{a}=20$ and $50 \mu \mathrm{A}$, respectively. The slope of the recruitment curve was much smaller $\left(S_{50}=2.4\right)$ when the anodal current $A_{a}$ and the cathodal current $A_{c}$ were increased simultaneously, according to the linear relation between $A_{a}$ and $A_{c}$ shown in the inset of Fig. 7(d). The recruitment curve and its slope $S_{50}$ changed when another linear relation between $A_{a}$ and $A_{c}$ was used. Five other sets of force recruitment curves measured under various conditions (not shown) gave the same effect: in comparison to experiments with a fixed value of $A_{a}$, the slope of the recruitment curve was strongly reduced when the anodal current $A_{a}$ was increased linearly with the cathodal current $A_{c}$.

As shown in the experimental curves [Figs. 4(c), and 7(c)-(d)] the variation in twitch force was rather large when stimulation was repeated with the same currents. The standard deviation of twitch force, at a stimulus amplitude corresponding to $50 \%$ force level, was about $0.07 \mathrm{~N}$ (100 measurements, maximum twitch force of the triceps surae was $2.2 \mathrm{~N}$ ). The standard deviation was the same when stimulating with one or two current sources.

\section{DISCUSSION}

In this study we have shown that a nerve fascicle can be stimulated selectively, without stimulating other fascicles when using a multigroove electrode. Crosstalk to a neighboring fascicle is not a problem, as can be concluded from both simulations and experiments. The value of the crosstalk parameter $R$ varied between two and ten in most experiments and simulations. Crosstalk may occur from a large fascicle being stimulated to a small neighboring fascicle.

The experiments were performed on EDL and triceps surae muscles of the rat. The weight factors used for the calculation of the force recruitment curves, however, were based on the diameter distribution of motor nerve fibers innervating the EDL of the cat. The diameter distribution of motor nerve fibers innervating the triceps surae of the cat is not available from literature. The results showed, however, that a force recruitment curve closely resembles the nerve recruitment curve of the nerve fiber diameter $(D=13.5 \mu \mathrm{m})$, having the largest weight factor. For the medial gastrocnemius of cat [33] the largest weight factor is found for $D=14.5 \mu \mathrm{m}$, but differences in $A_{10}$ and $S_{50}$ between the nerve recruitment curves for $D=13.5$ and $14.5 \mu \mathrm{m}$ were small (Fig. 3). Therefore, the results will change only slightly when another realistic motor nerve fiber diameter distribution is used to calculate the weight factors and the force recruitment curves.

The threshold stimulus for the common peroneal nerve (small fascicle) was lower than for the tibial nerve (large fascicle) in both experiments and simulations. This difference is probably related to the different cross sections of the two nerves (and the correspondingly sized grooves). The current density in the (smaller) common peroneal nerve and its derivative along the nerve axis (the activating function [35]) will be higher than in the tibial nerve when applying the same stimulus current. Furthermore, the electrical impedance of the perineurium around the common peroneal nerve is lower than around the tibial nerve, because the thickness of the perineurium is related to the diameter of the fascicle [15]. These two aspects will cause the lower threshold for stimulation of the common peroneal nerve. For the same reasons threshold for crosstalk from the tibial nerve (large fascicle) to the common peroneal nerve (small fascicle) was lower (parameter $R$ smaller) than vice versa, as observed in both experiments and simulations. Threshold stimulus is also affected by the nerve fiber diameter distribution. The medial gastrocnemius, which is a part of the triceps surae, is innervated by nerve fibers with larger diameters than the EDL [33]. An increase in fiber diameter of $1 \mu \mathrm{m}$ causes a reduction in threshold stimulus of about $1 \mu \mathrm{A}$ (Fig. 3). This is only a small effect (in opposite direction) as compared to the difference in thresholds of tibial nerve and common peroneal nerve.

The simulations predict that threshold stimuli decrease when the saline layer between fascicle and groove is replaced by fibrous tissue (Table III), the latter having a much lower conductivity. This effect will be due to a reduced current leakage from cathode to anode via this intermediate layer. This (qualitative) model prediction is confirmed by experimental results, where threshold stimuli decreased when the well conducting Ringer solution in the groove was replaced by nonconducting liquid paraffin (except at the extending contacts). Although the thickness of the intermediate layer 


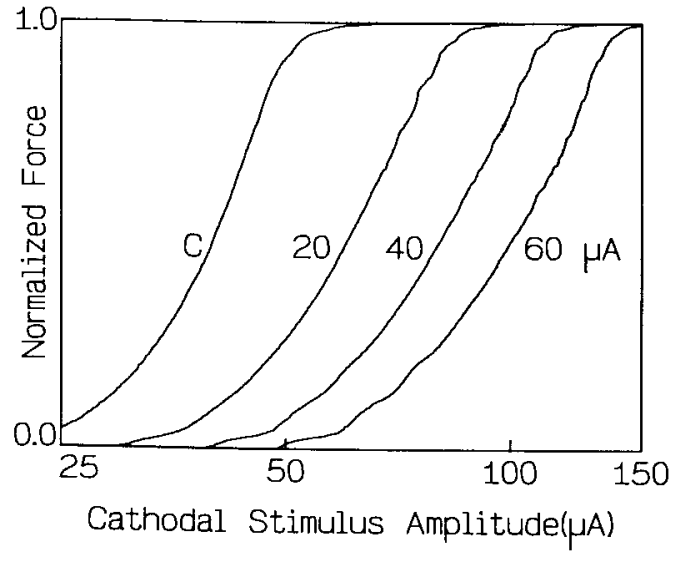

(a)

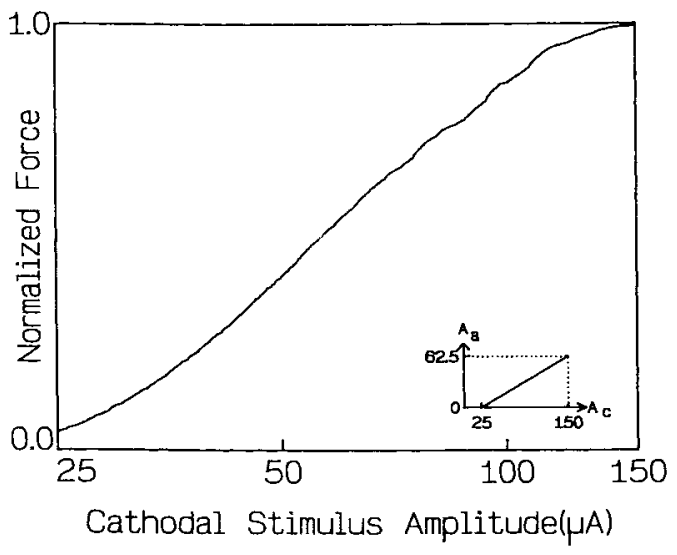

(b)

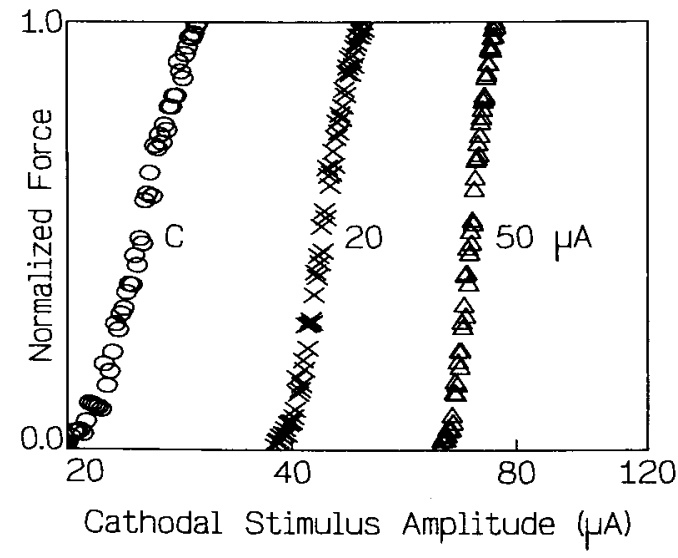

(c)

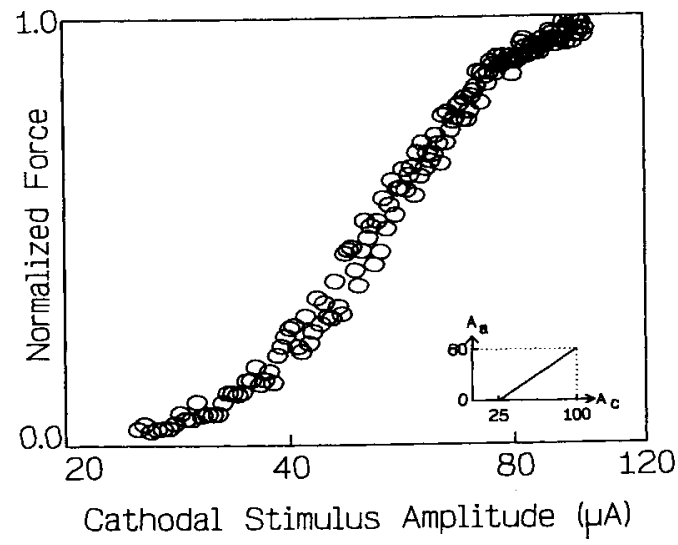

(d)

Fig. 7. (a) Force recruitment curves calculated with model of Fig. 2(c); monopolar cathodal stimulation (curve $C$ ) and stimulation with two current sources [cf. Fig. 2(c)], the anodal current having a fixed value $(20,40,60 \mu \mathrm{A})$. (b) Calculated force recruitment curve for stimulation with two current sources, the anodal current $\left(A_{a}\right)$ being linearly related to the cathodal current $\left(A_{c}\right)$ as shown in inset. (c) Experimental recruitment curves of triceps surae, the tibial nerve being stimulated monopolarly $(C)$, or using two current sources, the anodal current having a fixed value (20, $50 \mu \mathrm{A})$. (d) Experimental recruitment curve when stimulating with two current sources, anodal current $\left(A_{a}\right)$ being linearly related to cathodal current $\left(A_{c}\right)$ as shown in inset.

in the experiments is not known and the conductivities of fibrous tissue and liquid paraffin surely are not the same, it can be concluded that in order to keep stimulus currents low, the amount of (conducting) medium between groove and perineurium should be small.

The simulations also predict that the slope $\left(S_{50}\right)$ of the force recruitment curve increases when the fibrous tissue layer is replaced by well conducting saline (Table III). This is not supported by the experimental results, however, which may be due to the large standard deviations. The slope of the recruitment curves is relevant with regard to an accurate force control. A general problem in nerve stimulation by a cuff electrode is the steepness of the slope of the recruitment curves [7], [36]. The simulations (Table III) indicate that the smallest slopes of recruitment curves, just like the lowest thresholds, are obtained when the amount of conducting tissue between contact and perineurium is small. This conclusion is supported by the simulation data in Table IV.

Another advantage of only a small amount of tissue (or a small distance) between contact and perineurium is a low value of the parameter for inverse recruitment order at a low recruitment level. The simulation results indicate that inverse recruitment order becomes less pronounced when the distance between contact and fascicle is reduced (Fig. 6). This is in accordance with results by Veltink et al. [10], [16], [37], who found mixed recruitment when intrafascicular electrodes, being still closer to the nerve fibers, were used.

From the simulations (Table IV) it can be concluded that a cathode with a small size in the $x, y$-plane is preferable to a large one, because the slope of the force recruitment curve was smaller than for a wider cathode, especially at low recruitment levels [Fig. 5(a)]. Unfortunately, this conclusion was not confirmed by experiments using contacts of different dimensions, because these experiments (not shown) had large standard deviations. Another advantage of a small contact is that at low recruitment levels inverse recruitment was less pronounced for a small contact than for a larger one (Fig. 6). Furthermore, complementary halves of a fascicle can be recruited separately by two contacts at opposite sides of the fascicle, using monopolar cathodal stimulation [25]. It may thus be possible to reduce muscle fatigue by stimulating the two halves alternately, similar to caroussel stimulation 
[8]. Selective stimulation of subpopulations within a single fascicle and reduced fatigue can also be achieved when using intrafascicular electrodes [11], [38].

Stimulation by a cathode and an anode, opposite to each other and driven by two current sources, offers the possibility to reduce the slope of the recruitment curve considerably. The slope was large when the fascicle was stimulated monopolarly by a cathode, or when the variable cathodal current was combined with a fixed anodal current. Sweeney et al. [17] found, in their nerve trunk model, a slight decrease of the slope of the recruitment curve when a "steering" anode was used in addition to monopolar cathodal stimulation. However, a much smaller slope can be obtained when anodal and cathodal currents are varied simultaneously [Fig. 7(b), (d)], providing the right (linear) relation between anodal and cathodal current is selected. These results are in accordance with those obtained with a multipolar nerve cuff electrode [19]. The method presented here is less complicated, however, because it is not necessary to worry about fascicle selectivity. The small slope of the recruitment curve may be favorable for an accurate force control. However, twitch force is not highly reproducible (standard deviation about 7\%). A better result may be obtained when the fascicle is stimulated by a pulse sequence generating a tetanic force. A drawback of the method may be that higher stimulus currents are needed than in monopolar cathodal stimulation, especially at high recruitment levels.

When applying the multigroove electrode, the external epineurium has to be opened and the epineurial tissue between the fascicles has to be dissected, while leaving the perineurium around the fascicles intact. This is a wellestablished microsurgical technique in nerve repair [39]. Longitudinal incisions in the epineurial tissue should be made carefully under a microscope, respecting the intraneural longitudinal microvasculature. Some injury can be tolerated, due to the numerous anastomoses and a quick revascularization [15], [40]. Elongation of the nerve, as enabled by its elasticity and ability to glide in the surrounding tissue, should be limited to the normal in-situ range (a few percent of the nerve length) [41]. In intradural sacral anterior root stimulation for bladder control (the Brindley method) it is common practice to split the posterior and anterior roots [24]. The latter (usually being a single fascicle) are placed in the "books" and the bladder can be stimulated during many years, indicating that nerve injury is not a serious problem under these conditions. In chronic applications of the multigroove electrode the grooves have to be closed to prevent the fascicles from slipping out. This should be done in a way that does not lead to nerve injury, e.g., similarly as for the Brindley book electrode [23], leaving sufficient open space under the cover for fibrous tissue growth. In order to minimize mechanical irritation, resulting in excessive fibrous tissue growth, the grooves should have a smooth surface. Therefore, the contacts should be embedded in the silicone rubber.

Although from a functional point of view the multigroove electrode is a potentially appropriate device for applications in multichannel FES systems, it has to be tested for possible nerve damage under chronic conditions and the design has to be optimized for chronic use.

\section{ACKNOWLEDGMENT}

The authors wish to thank H. E. van der Aa (Medisch Spectrum Twente Hospital, Enschede) for helpful discussions and suggestions. Furthermore, they thank R. Busschers and J. H. M. Put for animal preparation and support during the experiments.

\section{REFERENCES}

[1] U. Stanic, R. Acimovic-Janezic, N. Gros, A. Trnkoczy, T. Bajd, and M. Kljajic, "Multichannel electrical stimulation for correction of hemiplegic gait," Scand. J. Rehab. Med., vol. 10, pp. 75-92, 1978.

[2] C. W. Caldwell and J. B. Reswick, "A percutaneous wire electrode for chronic research use," IEEE Trans. Biomed. Eng., vol. BME-22, pp. 429-432, 1975.

[3] E. B. Marsolais and R. Kobetic, "Functional electrical stimulation for walking in paraplegia," J. Bone Joint Surg., vol. 69-A, pp. 728-733, 1987.

[4] D. Popovic, T. Gordon, V. F. Rafuse, and A. Prochazka, "Properties of implanted electrodes for functional electrical stimulation," Ann. Biomed. Eng., vol. 19, pp. 303-316, 1991.

[5] P. A. Grandjean and J. T. Mortimer, "Recruitment properties of monopolar and bipolar epimysial electrodes," Ann. Biomed. Eng., vol. 14, pp. 53-66, 1986

[6] D. R. McNeal and B. R. Bowman, "Selective activation of muscles using peripheral nerve electrodes," Med. Biol. Eng. Comput., Vol. 23, pp. 249-253, 1985

[7] G. G. Naples, J. T. Mortimer, A. Scheiner, and J. D. Sweeney, "A spiral cuff electrode for peripheral nerve stimulation," IEEE Trans. Biomed. Eng., vol. 35, pp. 905-916, 1988.

[8] J. Holle, M. Frey, H. Gruber, H. Kern, H. Stöhr, and H. Thoma, "Functional electrostimulation of paraplegics. Experimental investigations and first clinical experience with an implantable stimulation device," Orthoped., vol. 7, pp. 1145-1155, 1984.

[9] B. R. Bowman and R. C. Erickson, "Acute and chronic implantation of coiled wire intraneural electrodes during cyclical electrical stimulation," Ann. Biomed. Eng., vol. 13, pp. 75-93, 1985.

[10] P. H. Veltink, J. A. van Alsté, and H. B. K. Boom, "Multielectrode intrafascicular and extraneural stimulation," Med. Biol. Eng. Comput., Vol. 27, pp. 19-24, 1989.

[11] K. Yoshida and K. Horch, "Selective stimulation of peripheral nerve fibers using dual intrafascicular electrodes," IEEE Trans. Biomed. Eng., vol. 40, pp. 492-494, 1993.

[12] J. H. Meier, W. L. C. Rutten, and H. B. K. Boom, "Force recruitment during electrical nerve stimulation with multipolar intrafascicular electrodes," Med. Biol. Eng. Comput., vol. 33, pp. 409-417, 1995.

[13] J. T. Mortimer, W. F. Agnew, K. Horch, P. Citron, G. Creasey, and C. Kantor, "Perspectives on new electrode technology for stimulating peripheral nerves with implantable motor prostheses," IEEE Trans. Rehab. Eng., vol. 3, pp. 145-154, 1995.

[14] G. G. Naples, J. T. Mortimer, and T. G. H. Yuen, "Overview of peripheral nerve electrode design and implantation," in Neural Prostheses, Fundamental Studies, W. F. Agnew and D. B. McCreery Eds. Englewood Cliffs, NJ: Prentice Hall, 1990.

[15] S. Sunderland, Nerves and Nerve Injuries, 2nd ed. London, England: Churchill Livingstone, 1978.

[16] P. H. Veltink, B. K. van Veen, J. J. Struijk, J. Holsheimer, and H. B. K Boom, "A modeling study of nerve fascicle stimulation," IEEE Trans. Biomed. Eng., vol. 36, pp. 683-692, 1989.

[17] J. D. Sweeney, D. A. Ksienski, and J. T. Mortimer, "A nerve cuff technique for selective excitation of peripheral nerve trunk regions," IEEE Trans. Biomed. Eng., vol. 37, pp. 706-715, 1990.

[18] J. A. Gruner and C. P. Mason, "Nonlinear muscle recruitment during intramuscular and nerve stimulation," J. Rehab. Res. Dev., Vol. 26, pp. $1-16,1989$.

[19] C. Veraart, W. M. Grill, and J. T. Mortimer, "Selective control of muscle activation with a multipolar nerve cuff electrode," IEEE Trans. Biomed. Eng., vol. 40, pp. 640-653, 1993.

[20] J. D. Sweeney, N. R. Crawford, and T. A. Brandon, "Neuromuscular stimulation selectivity of multiple-contact nerve cuff electrode arrays," Med. Biol. Eng. Comput., vol. 33, pp. 418-425, 1995.

[21] R. R. Chintalacharuvu, D. A. Ksienski, and J. T. Mortimer, "A numerical analysis of the electric field generated by a nerve cuff electrode," in IEEE Proc. 13th Ann. Conf. Med. Biol. Soc., 1991, pp. 912-913.

[22] W. M. Grill and J. T. Mortimer, "Stimulus waveforms for selective neural stimulation,” IEEE Eng. Med. Biol. Mag., vol. 14, pp. 375-385, 1995. 
[23] G. S. Brindley, "An implant to empty the bladder or close the urethra," J. Neurol. Neurosurg. Psych., vol. 40, pp. 358-369, 1977.

[24] G. S. Brindley, C. E. Polkey, D. N. Rushton, and L. Cardozo, "Sacral anterior root stimulators for bladder control in paraplegia: The first 50 cases," J. Neurol. Neurosurg. Psych., vol. 49, pp. 1104-1114, 1986.

[25] P. Koole and J. Holsheimer, "Multi-groove electrode for fascicle selective nerve stimulation," in Advances in External Control of Human Extremities, X, D. B. Popovic, Ed. Belgrade, Yugoslavia: 1990, pp. 307-317.

[26] W. M. Grill and J. T. Mortimer, "Electrical properties of implant encapsulation tissue," Ann. Biomed. Eng., vol. 22, pp. 23-33, 1994.

[27] J. J. Struijk, J. Holsheimer, G. Barolat, J. He, and H. B. K. Boom, "Paresthesia thresholds in spinal cord stimulation: A comparison of theoretical results with clinical data," IEEE Trans. Rehab. Eng., vol. 1, pp. 101-108, 1993.

[28] A. Weerasuriya, R. A. Spangler, S. I. Rapoport, and R. E. Taylor, "AC impedance of the perineurium of the frog sciatic nerve," Biophys J., vol. 46 , pp. 167-174, 1984 .

[29] L. A. Geddes and L. E. Baker, "The specific resistance of biological material-A compendium of data for the biomedical engineer and physiologist," Med. Biol. Eng., vol. 5, pp. 271-293, 1967.

[30] D. R. McNeal, "Analysis of a model for excitation of myelinated nerve," IEEE Trans. Biomed. Eng., vol. BME-23, pp. 329-337, 1976.

[31] J. J. Struijk, J. Holsheimer, G. G. van der Heide, and H. B. K Boom, "Recruitment of dorsal column fibers in spinal cord stimulation: Influence of collateral branching," IEEE Trans. Biomed. Eng., vol. 39, pp. 903-912, 1992.

[32] S. Y. Chiu, J. M. Ritchie, R. B. Rogart, and D. Stagg, "A quantitative description of membrane currents in rabbit myelinated nerve," J. Physiol, vol. 292, pp. 149-166, 1979.

[33] I. A. Boyd and M. R. Davey, Composition of Peripheral Nerves. London, England: E \& S Livingstone Ltd., 1968.

[34] D. M. Lewis, "The physiology of motor units in mammalian skeletal muscle," in Handbook of Behavioral Neurobiology, Motor coordination, A. L. Towe and E. S. Luschei, Eds. New York: Plenum, vol. 5, 1981, pp. $1-66$.

[35] F. Rattay, "Analysis of models for external stimulation of axons," IEEE Trans. Biomed. Eng., vol. BME-33, pp. 974-977, 1986.

[36] P. H. Gorman and J. T. Mortimer, "The effect of stimulus parameters on the recruitment characteristics of direct nerve stimulation," IEEE Trans. Biomed. Eng., vol. 30, pp. 407-414, 1983.

[37] P. H. Veltink, J. A. van Alsté, and H. B. K. Boom, "Simulation of intrafascicular and extraneural nerve stimulation," IEEE Trans. Biomed. Eng., Vol. 35, pp. 69-75, 1988.

[38] K. Yoshida and K. Horch, "Reduced fatigue in electrically stimulated muscle using dual channel intrafascicular electrodes with interleaved stimulation," Ann. Biomed. Eng., vol. 21, pp. 709-714, 1993.

[39] J. W. Tupper, J. C. Crick, and L. R. Matteck, "Fascicular nerve repairs, a comparative study of epineurial and fascicular (perineurial) techniques," Orthoped. Clin. North Amer., vol. 19, pp. 57-69, 1988.

[40] G. Lundborg, "Structure and function of intraneural microvessels as related to trauma, edema formation, and nerve function," J. Bone Joint Surg., vol. 57-A, pp. 938-948, 1975.

[41] H. Millesi, G. Zöch, and R. Reishner, Mechanical properties of peripheral nerves," Clin. Orthopaed. Rel. Res., no. 314, pp. 76-83, 1995.

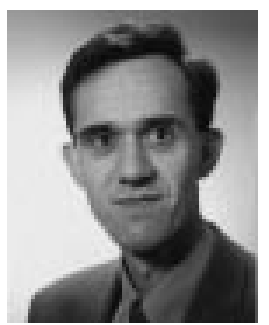

Paul Koole was born in 1955 in Marknesse, The Netherlands. He received the M.Sc. degree in physics from the University of Groningen, The Netherlands, in 1979 and the Ph.D. degree in biophysics from the University of Utrecht, The Netherlands, in 1984. The subject of his dissertation was electron spin resonance studies of molecular dynamics in lipid bilayers.

His interests and experience are in several areas of application of physics such as telecommunication, defense systems, and biomedical engineering. In the latter area, his interests mainly focus on two topics. In the field of hyperthermia, he has worked on the development of a coaxial microwave applicator and the comparison of fractionation: schemes of combined cancer therapy by hyperthermia and/or irradiation. In the field of rehabilitation engineering, he has worked on the development of an electrode for the selective stimulation of nerve fascicles by acute experiments and computer modeling.

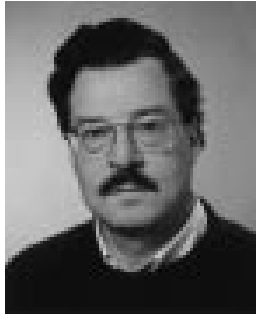

Jan Holsheimer was born in Enschede, The Netherlands, in 1941. He received the M.Sc. degree in biology and biophysics from the University of Groningen, The Netherlands, in 1965, and the Ph.D. degree in biomedical engineering from the University of Twente, Enschede, The Netherlands, in 1982.

In 1965, he joined the Biomedical Engineering Division in the Department of Electrical Engineering at the University of Twente, where he had first engaged in the recording, analysis, and modeling of field potentials in cortical brain structures. Since 1986, his primary research interests are the theoretical, experimental, and clinical aspects of electrical nerve stimulation in the spinal cord and peripheral nerves.

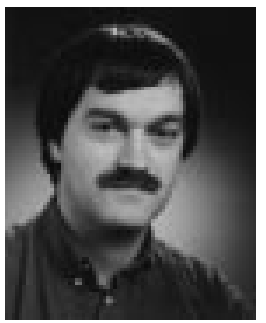

Johannes J. Struijk was born in Rijssen, The Netherlands, in 1963. He received the M.Sc. degree in electrical and biomedical engineering in 1988 and the Ph.D. degree in electrical engineering in 1992 from the Biomedical Engineering Division at the University of Twente, Enschede, The Netherlands.

After two years as a Postdoctoral Fellow at the University of Twente, he joined the Center of Sensory-Motor-Interaction at Aalborg University, Denmark, where he is currently an Assistant Professor. His research interests are in electrical and magnetic nerve stimulation, neuroprostheses, volume conduction, and bioelectricity.

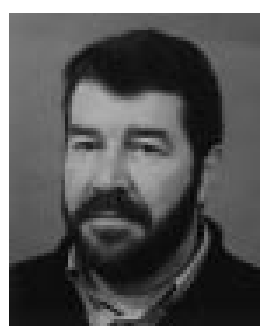

Anton J. Verloop was born in Voorburg, The Netherlands, in 1944. He received degrees with specialization in fine-mechanics from the Technical University of Delft, Delft, The Netherlands.

Since 1961, he worked in the Department of Fine Mechanics at the Technical University of Delft. In 1971, he joined the Biomedical Engineering Division in the Department of Electrical Engineering at the University of Twente, The Netherlands. His main interests and skills are the design and fabrication of devices for recording and stimulation of the neuromuscular system, like multi-(wire) electrodes, nerve cuffs, and flexible leads for implants. 